\title{
Science and Hypothesis: An Evaluation on Oral Vestibular Schwannoma Growth from the Viewpoint of Molecular Biology
}

\author{
Bing Tang* \\ Columbia University, USA \\ *Corresponding author: Bing Tang, MPH, Master of Public Health, Columbia University, New York, USA \\ Submission: May 18, 2018; Published: June 06, 2018
}

\section{Introduction}

This author has known Medical Hypotheses several years ago, unfortunately did not know that it is available online until lately, when he read Prof. Gong Peng's important hypotheses. This author has been honored to receive the invitation from Prof. Ping Gong [an oral surgeon in China] for our potential collaboration in the near future. In the meantime, please correct some possible errors in this author's own writing as presented below, and the possibility of applying his own concepts into the important future research. In fact, science in Latin means to know. And, religion means to cultivate (cult, cultus, and agriculture). Science aims to know what God created, while religion in Christian sense aims to cultivate a closer relationship with the creator/savior Himself.

Combining the two is significant, since we will know both the creator/savior and the created. Science and religion, while not mutually exclusive, are orthogonal concepts. Science is an explanatory system intended to answer the question, "How?" E.g., how do mitochondria act as energy plants for cells? Religion, conversely, is an explanatory system intended to answer the question "Why?" E.g., why are we here? Why do we die? If we are Combining the two different systems together, capriciously and arbitrarily, it will be a risky venture and is beyond the purview of any scientific publisher.

This author once wrote that through certain imaginary revolution in medical science, we may be thus witnessing the language in which God created life and we are more in awe of the wonder and complexity of God's most sacred gift." The statement was written within the context of the successful completion of Human Genome Project. From a Christian perspective, this author thought of this milestone as a complementary relationship of faith in Jesus Christ and science. Why can't they statement God of the Bible be the God of the Genome? Therefore, this author disagrees with any statement that this author has assumed any "priori" the existence of God before the presentation of actual data. However, this author will agree that he does have his own strong and keen belief system. That has been said, any criticism of using 'logical tautologies' within the expression confounds and intrigues this author. We all should avoid beating about the bush. As a religious believer, this author does look at science as a mean of exploring nature and at the same time, science as a mean of exploring and appreciating God's creative abilities for sure.

As to Mitochondria is concerned, it should be followed with an explanation for ATP [Namely. adenosine triphosphate as its full name, to be sure.] Mitochondria should be a subject in the biochemistry textbook in the first year of Medical School curriculum. It is a cellular organelle where, among several tasks, while the ' 3 carbon sugars' are oxidized and an ATP is produced, which the cell uses as an energy source. In the Old Testament bible, we can find and appreciate the following two important verses:

a) GENESIS 22:14 And Abraham called the name of that place Jehovah jireh: as it is said to this day, in the mount of the LORD it shall be seen. Jehovah jireh: that is, The Lord will see, or, provide.

b) EXODUS 6:2 And God spa problem seems to beke unto Moses, and said unto him, I am the LORD: or the LORD: or, JEHOVAH.

The problem seems to be as following, only after reader's clicking on https://www.youtube./watch?time_ continue $=585 \& \mathrm{v}=$ wRsbSLU9oFA to hear how this person guesses how it is pronounced. He admits that he is only guessing. No one knows how it was actually pronounced.

\section{Vestibular Schwannoma Growth}

This author read with great interest the article written by Baser et al. [1]. Their research expresses result of two longitudinal studies of growth rates of vestibular schwannomas (VSs) in patients with neurofibromatosis Type 2 (NF2) differs from each other as to 
whether VS growth rates decrease or increase whenever patients getting older. The authors undertook their study to assess the relationship between VS growth rates and patient age and type of constitutional NF2 mutation; they also examined the in VS growth rates among multiple patients in families with NF2. Methods by using Gadolinium-enhanced magnetic resonance images obtained in 18 patients with inherited NF2 from 11 unrelated families whom were retrospectively analyzed. The patients had been observed for a period with a median of 4 years. Volumes of the VSs were checked using a two-component box model (intrameatal and extrameatal parts checked respectively). Single-strand conformation polymorphism analysis and Southern blot analysis were employed to constitutional NF2 mutations. Growth rates of the VSs were highly flexible but have a tendency to diminution with increasing patient age both at commencement of signs or symptoms of NF2 ( $\mathrm{r} 2=0.35$, $\mathrm{p}=0.026)$ and at diagnosis $(\mathrm{r} 2=0.33, \mathrm{p}=0.012)$. The VS growth rates did not fluctuate significantly with the type of constitutional NF2mutation or the number of non-VS either cerebral or spinal tumors. The VS growth rates were highly modifiable within families, but, did not correspond to clinical pictures of NF2 disease severity, such as patient age at the symptom commencement and the actual numbers of non-VS cerebral and spinal tumors respectively.

Conclusions of their study can be summarized as following-the growth rates of VSs in patients with NF2 are highly variable but tend to decrease with increasing patient age. Clinical treatment of multiple patients in families with NF2 cannot be based on the expectations of similar VS growth rates, even when other clinical aspects of disease severity are so close to each other, the latter including other nervous system tumors' occurance rate.

Being due to the fact that vestibular schwannomas also develop sporadically, and the other fact of their onset usually takes place when the patient is older. Age per se, however, does not explain the detected difference in proliferation of tumors. One of the explanations is that VSs in younger patients with NF2 also had higher MIB-1 indices (Ki-67; monoclonal antibodies) than their counterparts, sporadic tumors in age-matched patients; this is why MIB-1 monoclonal antibody testing is so much useful. It is also very interesting and important that within spinal tumors, malignant peripheral nerve sheath tumors have higher MIB-1 pictures.

Though the defective NF2 gene is important in the tumorigenesis of both NF2 and sporadic schwannomas, the differences in the molecular biology of these tumors, rather than any difference in ages among the patients are crucial [2]. This author certainly agrees with the authors that there are marked interfamily differences in disease severity and tumor susceptibility in NF2 [3]. In fact, larger acoustic neuromas were more commonly found in patients with concomitant spinal tumors or meningiomas. Patients with NF2 with spinal tumors but not meningiomas demonstrated faster growth rates than patients without any additional tumor in another part of the nervous system. Analysis of the data from the study by Dr. Abaza et al. [2], indicates that patient with associated spinal tumors have faster growing acoustic neuromas and therefore should be followed closely and treated even more aggressively. Any allocation of patients with VS to the so-called wait-and-see treatment policy, in this author's opinion, must be more thoroughly assessed and reevaluated [4]

With regard to molecular biology, paying special attention to the genotype-phenotype correlation in NF2, we now know that the splice-site mutations in NF2 are associated with various phenotypes, which range from severe to symptom free. In addition to interfamily differences, phenotypic variations are also observed within families. Mutations downstream from exon 8 (in contrast to intron, extron is a segment of a gene that is decoded to provide a messenger RNA or mature RNA product) result more often in mild phenotypes of NF2. This indicates that splice-site alteration is a relatively common cause of NF2, and that splice-site alteration does not look like any other mutations; the clinical outcomes of splice-site mutations in the NF2 gene are quite variable. For this very reason, the tremendously growing volume of information on genotype-phenotype correlation in NF2 has been enlarged and expanded [1]

On the other hand, the missense mutation (that is, a nucleotide substitution that results in an amino acid change) does take place in patients with mild phenotypes, in contrast to the splice-site mutation, which occurs in families with both mild and severe phenotypes of NF2. It is worthwhile to note that truncating mutations of NF2 are usually associated with severe phenotypes, but the association of some mutations with mild and severe phenotypes indicates that NF2 expression is affected by stochastic, epigenetic, or environmental factors [5]. In my professional opinion, and with a reasonable degree of medical certainty, mental factors (as in the spiritual dimension) might also play a role. Last but not the least, in a larger study of 132 unrelated families reported by Trueman et al. [5], the authors, Evans et al. [6] have successfully confirmed the previous impression that truncating mutations are associated with a severe form of NF2. Nonetheless, due clinical sentences are still needed to be exercised to use mutation types for predicting the disease course of NF2. This author encourages Dr. Baser et al. [1] for their fine quality of their work, and sincerely hopes that in the near future they can find any other possible predictors of VS growth rates in patients with NF2 $[7,8]$.

\section{References}

1. Kluwe L, Bayer S, Baser ME, Hazim W, Haase W, et al. (1996) Identification of NF2 germline mutations and comparison with neurofibromatosis 2 phenotypes. Hum Genet 98(5): 534-538.

2. Abaza MM, Makariou E, Armstrong M, Lalwani AK (1996) Growth rate characteristics of acousticneuromas associated with neurofibromatosis type 2. Laryngoscope 106(6): 694-699.

3. Charabi S, Thomsen J, Mantoni M, Charabi B, Jørgensen B, et al. (1995) Acoustic neuroma (vestibular schwannoma): growth and surgical and nonsurgical consequences of the wait-and-see policy. Otolaryngol Head Neck Surg 113(1): 5-14

4. Antinheimo J, Haapasalo H, Seppala M, Sainio M, Carpen O, et al. (1995) Proliferative potential of sporadic and neurofibromatosis 2-associated schwannomas as studied by MIB-1 (Ki-67) and PCNA labeling. ] Neuropathol Exp Neurol 54(6): 776-782. 
5. Trueman L, Evans DG, Wallace A, Collins S, Strachan T, et al. (1998) Genotype/phenotype correlations in type 2 neurofibromatosis (NF2): evidence for more severe disease associated with truncating mutations. J Med Genet 35(6): 450-455.

6. Evans DG, Huson SM, Donnai D, Neary W, Blair V, et al. (1992) A clinical study of type 2 neurofibromatosis. Q J Med 84(304): 603-618.
7. Tang B (200) Predictors of vestibular schwannoma growth in patients with neurofibromatosis Type 2. J of Neurosurgey 100: 734.

8. Kluwe L, Mac Collin M, Tatagiba M, Thomas S, Hazim W, et al. (1998) Phenotypic variability associated with 14 splice site mutations in the NF2 gene. Am J Med Genet 77(3): 228-233.
Creative Commons Attribution 4.0 International License

For possible submissions Click Here

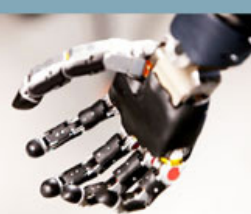

Submit Article

\section{Significances of Bioengineering \& Biosciences}

\section{Benefits of Publishing with us}

- High-level peer review and editorial services

- Freely accessible online immediately upon publication

- Authors retain the copyright to their work

- Licensing it under a Creative Commons license

- Visibility through different online platforms 